\title{
Pressure-Volume-Temperature Behavior of Carbon Tetrafluoride Using a Variable-Volume Cell of Bellows Design
}

\author{
J. J. MARTIN and R. K. BHADA \\ University of Michigan, Ann Arbor, Michigan
}

This paper presents data observed for the pressure-volume-temperature (P.V.T) behavior of carbon tetrafluoride $\left(\mathrm{CF}_{4}\right)$ below room temperature, and uses these data in conjunction with higher temperature data from the literature to evaluate an equa. tion of state. The P.V.T measurements were made via a variable-volume technique without using a confining liquid. The variable-volume design makes it possible to cover a range of specific volumes with a single charge, resulting in on efficient operating procedure.

A unique bellows design with a 14-fold volume variation was developed. The bellows contained the compound under study $\left(\mathrm{CF}_{4}\right)$ and was surrounded by a hydraulic liquid whose pressure could be varied causing the bellows to expand or contract. The volume of the bellows was determined by measuring the volume of the hydraulic liquid. Calibrations were made using a gas $\left(\mathrm{CO}_{2}\right)$ of known thermodynamic properties. Pressure measurements were made via a differential pressure transducer on three Heise gauges calibrated in place against a Ruska dead-weight tester. The bellows cell was maintained in a well-agitated bath whose temperature was measured by a platinum resistance thermometer.

The data were taken by charging a known amount of the compound into the bellows and observing the pressure-volume relationship at a fixed bath temperature. At the end of a run, the charge was recovered, the amount recovered agreeing within $0.01 \%$ with the amount charged.

The observed data were analyzed graphically on pressure-volume, pressuretemperature, and compressibility diagrams. Very good consistency was observed with the higher temperature data from literature. The data were correlated analytically with the Martin equation of state. This equation represents all the data with an average deviation of $0.25 \%$.

Carbon tetrafluoride (sometimes referred to as tetrafluoromethane or Freon 14) belongs to a group of chloro-fluoro compounds that have found considerable use as refrigerants. To facilitate the design of equipment using carbon tetrafluoride, thermodynamic properties such as entropy, enthalpy, and specific volume are needed at various temperatures and pressures. These properties may be evaluated from experimental determinations such as vapor pressure, liquid density, pressure-volume-temperature (P-V-T) behavior, and specific heat. Vapor pressure, liquid density, heat capacity, and $\mathrm{P}-\mathrm{V}-\mathrm{T}$ properties above the ice point have already been reported in literature ( 1 to 6$)$. One of the purposes of the present program was to observe the P-V-T behavior of carbon tetrafluoride in the low-temperature region extending to about $50^{\circ} \mathrm{R}$. below the critical temperature $\left(409.48^{\circ} \mathrm{R}\right.$.) with some overlap of the literature data. This would permit, in conjunction with the literature data, to determine an equation of state for carbon tetrafluoride over a wide range of pressure, temperature, and specific volume.

A further objective of the work was to make the P-V-T measurements via a unique bellows-type variable-volume technique without using a confining liquid. The variablevolume design makes it possible to cover a range of specific volumes with a single charge, resulting in an efficient operating procedure.

R. K. B hada is with the Babcock \& Wilc ox Company, Alliance, Ohio.

\section{LITERATURE SEARCH}

\section{Carbon Tetrafluoride}

A literature survey of references related to the $(\mathrm{P}-\mathrm{V}-\mathrm{T})$ behavior of carbon tetrafluoride has shown that the only P-V-T data are reported by Douslin et al. $(3,4)$ and by MacCormack and Schneider $(5,6)$.

MacCormack and Schneider $(5,6)$, of the National Research Council of Canada, have obtained compressibility up to 50 atm. in the temperature range of $0^{\circ}$ to $400^{\circ} \mathrm{C} .\left(491.67^{\circ}\right.$ to $1211.67^{\circ}$ R.). Douslin et al. $(3,4)$, at the U.S. Bureau of Mines, have reported complete P-V-T data in the region $0^{\circ}$ to $350^{\circ} \mathrm{C}$. $\left(491.67^{\circ}\right.$ to $1121.67^{\circ} \mathrm{R}$.) and 15 to $394 \mathrm{~atm}$. They have been correlated by a Benedict-Webb-Rubin equation with an average deviation of about $0.555 \%$ and a maximum deviation of $3.17 \%$.

Other investigators have made measurements on other properties of carbon tetrafluoride. Chari (1) has reported vapor pressure, liquid density, and the critical properties. Martin and Hwang (2) have reported the constant-volume heat capacity.

\section{Equipment and Methods of P-V-T Measurements}

A review of literature for equipment for observing $\mathrm{P}-\mathrm{V}-\mathrm{T}$ behavior of fluids shows two basic types of equipment used: constant-volume equipment or variable-volume constant-temperature equipment.

The constant-volume cell usually consists of a fixedvolume vessel in which the (P-V-T) behavior is determined 
by measuring pressures for different temperatures to which the constant-volume vessel is exposed (7). In order to cover a range of specific volumes, different masses of the compound are charged to the constant-volume vessel, and this results in gross inefficiency.

A variable-volume equipment requires only a single charge of material to cover a wide range of specific volumes. Numerous investigators, dating back to Amagat's work of $1893(8)$, have used variable-volume cells to measure the P-V-T properties of fluids. Beattie (9) has measured the P-V-T behavior of gaseous mixtures using a steel bomb whose volume can be varied by injection of mercury. Several other investigators ( 10 to 21 ) have used very similar techniques. Some investigators $(5,6,22$ to 24$)$ have used a technique attributed to Burnett (22) of evaluating behavior of state of a compound which only involves very accurate measurement of the pressure and temperature of the gas. Bridgeman $(25,26)$ has proposed two other types of variable-volume equipment: piston and bellows. Several investigators have utilized these systems primarily for liquid compressibility measurements $(27,28)$. For such applications, the expansion (of the bellows or the piston travel) need not be very large (for example, 2 to 1 volume change would be satisfactory). However, literature reports no successful applications of such systems to P-V-T measurements involving the gaseous state (where zero leakage and large volume changes are prime requirements).

\section{EXPERIMENTAL WORK}

\section{Equipment}

A scheme of the experimental system is shown in Figure 1. Details of the P-V-T cell are shown in Figure 2. The bellows, containing the gas under study, are enclosed in a thick-walled cylindrical shell made of stainless steel.
Details of the bellows are shown in Figure 3. It is made of 316 stainless steel and is capable of expanding from a solid height of 1.26 to about $8.50 \mathrm{in}$. The minimum volume is about $3.4 \mathrm{cu}$. in. and maximum volume is about $47 \mathrm{cu}$. in., a volume change of approximately 14-fold. It should be pointed out that because of the stringent volume expansion and materials requirements the bellows had to be spec ifically designed (of particularshaped concentric rings welded at the inner and outer diameters) in consultation with engineers from Belfab Corporation, which also made the final construction.

The expansion and contraction of the bellows is achieved by release or forcing of the hydraulic fluid (propanol in this case) into the space between the bellows and the cylindrical shell via the leak-proof hydraulic system pump. The low-pressure end of the pump is connected to a fluid reservoir and a level-measurement glass gauge, $60 \mathrm{in}$. high. The level observed is related to the volume occupied by the gas in the bellows. This indication, after suitable calibration, is used for volume measurement.

The pressure measuring system consists of a Pace diaphragm pressure transducer leading to a set $(0$ to 100,0 to 500,0 to $2,000 \mathrm{lb} . / \mathrm{sq}$. in.) of very sensitive Heise pressure gauges calibrated by a Ruska dead-weight gauge tester. The diaphragm transducer is of the differential pressure type which indicates pressure imbalance on the two sides of the diaphragm. On one side of the diaphragm is the pressure of the compound in the bellows, and this pressure is balanced by pressure applied on the other side from a cylinder of nitrogen. When the diaphragm gauge indicator shows equalized pressure on both sides, then the pressure of the nitrogen side is measured by the set of accurate Heise gauges; three such gauges are used covering three pressure ranges. These pressure gauges are calibrated in place periodically by means of a Ruska dead-weight gauge tester. The temperature of the bath was measured very accurately with a platinum resistance thermometer in circuit with a Leeds and Northrup potentiometer and a lamp-and-scale galvanometer.

The evacuation and charging system includes a Cenco vacuum pump and a vacuum gauge, together with the large cylinder containing the compound to be charged and a smaller cylinder whose weight can be accurately determined. The compound is loaded into the smaller cylinder (called charge cylinder in $\mathrm{F}$ igure 1) prior to charging into the $\mathrm{P}-\mathrm{V}-\mathrm{T}$ cell. Weight measurements of this charge cylinder before and after charging (or recovery) indicate amount of compound charged (or recovered).

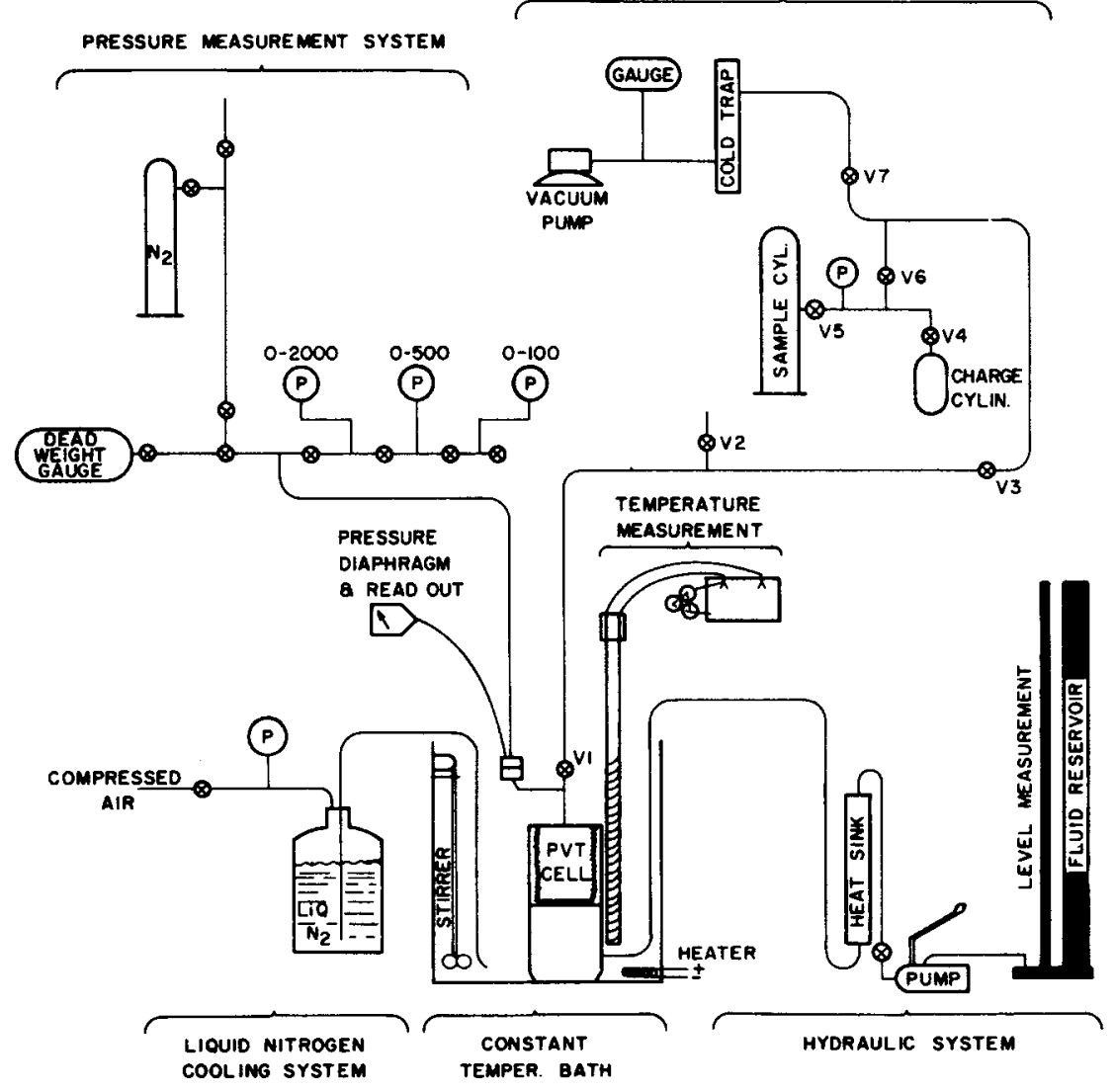

Fig. 1. System for measuring P-V-T behovior. 
The P-V-T cell was immersed in a bath filled with normal propanol which could maintain a constant temperature while pressure and volume readings were observed along an isotherm.

\section{Experimental Precision}

This section summarizes the estimated errors that might be involved in the measurements and calibrations. Details of this, as

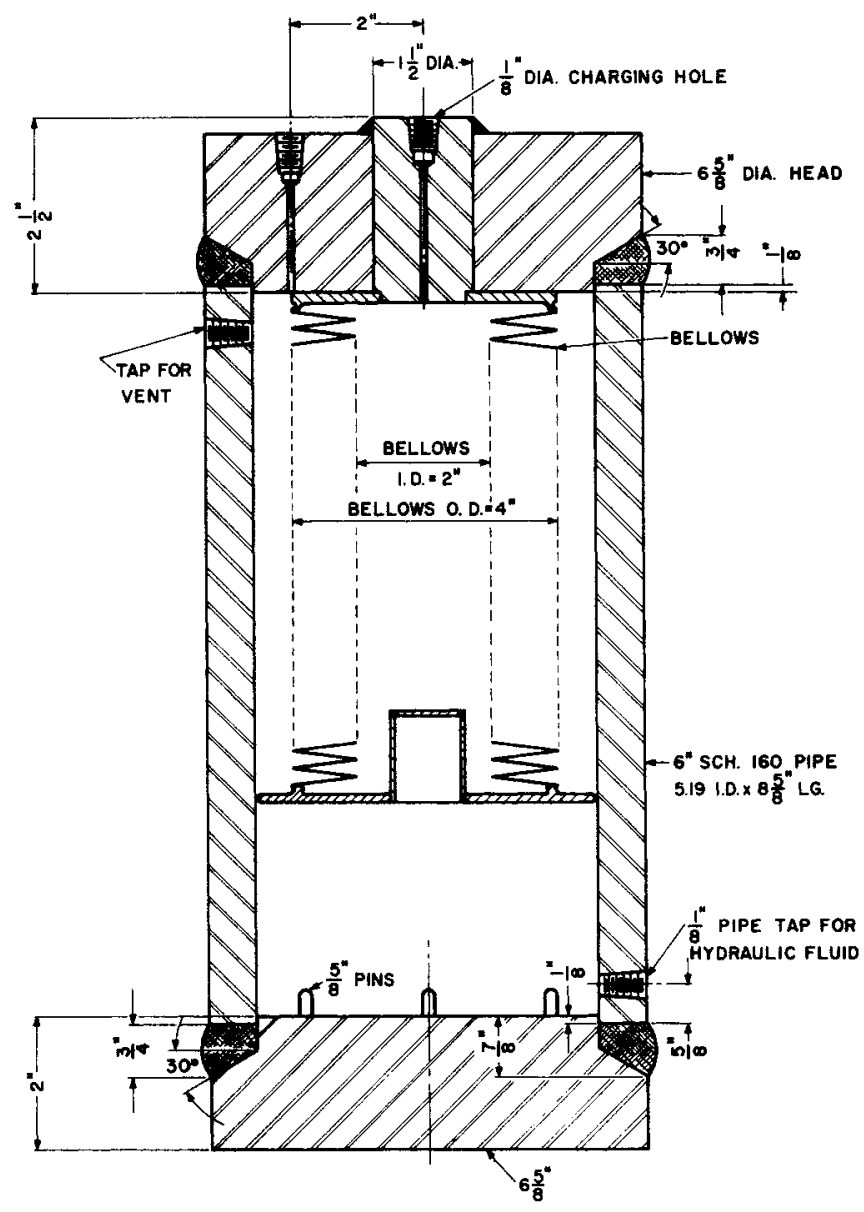

Fig. 2. Details of the P-V.T cell.

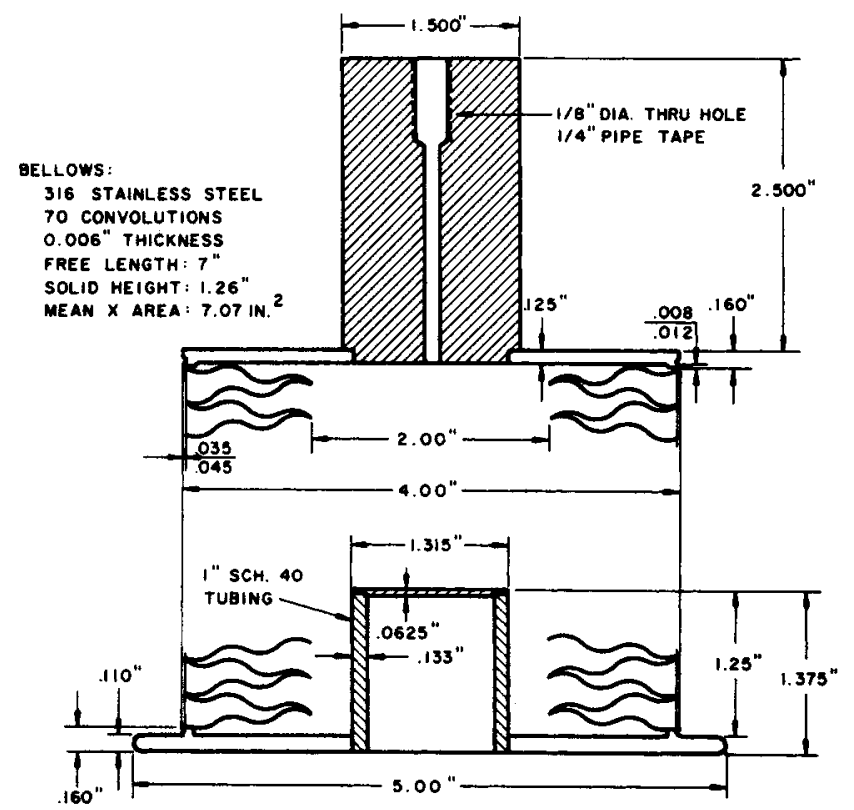

Fig. 3. Details of the bellows. well as other aspects of this paper, have been reported in a University of Michigan dissertation $(30)$.

Pressure testing of the P-V-T cell, at pressures ranging from 100 to $1,500 \mathrm{lb} . / \mathrm{sq}$. in. gauge, up to $24 \mathrm{hr}$. has shown absolutely no pressure drop. Furthermore, the very close check between the amount recovered and the amount charged $( \pm 0.005 \mathrm{~g}$.$) indicates$ that the P-V -T cell has essentially zero leakage.

The Freon-14 charged was specially prepared by the duPont Company for making P-V -T measurements. The compound contains less than $0.004 \% \mathrm{CClF}_{3}$ as impurity.

Errors in pressure, volume, and temperature measurement have been critically reviewed, and the following are the maximum errors expected:

1. Pressure: $\quad \pm 1 \mathrm{lb} . / \mathrm{sq}$. in. above $500 \mathrm{lb} . / \mathrm{sq}$. in. $\pm 0.26 \mathrm{lb} . / \mathrm{sq}$. in, between 100 to $500 \mathrm{lb} . / \mathrm{sq}$. in.

2. Volume:

. $\pm 1.3 \%$ at the smallest bellows volume $\pm 0.24 \%$ at the largest bellows volume

3. Temperature: $\pm 0.084^{\circ} \mathrm{F}$.

\section{RESULTS}

The laboratory data for carbon tetrafluoride, converted to pressure, specific volume, and temperature are reported in the first three columns of Table 1. These have been analyzed graphically as well as algebraically. These analyses have been made in conjunction with the literature reported data of Douslin et al. $(3,4)$ and of MacCormack and Schneider $(5,6)$.

\section{Graphical Analysis}

The data have been graphically analyzed by construction of a pressure-volume plot, a pressure-temperature plot, and a compressibility chart.

The pressure-volume diagram is shown in Figure 4; the saturation curve is from reference 1 . Within the limits of accuracy of the original diagram of Figure 4 (estimated to be $\pm 0.3 \%$ ), the data of this paper show very good agreement with the data of the literature in the regions of overlap. The diagram further illustrates the inflection properties of the isotherms, especially near the critical point.

The pressuretemperature diagram is shown in Figure 5. This illustrates the linearity of the isometrics near the

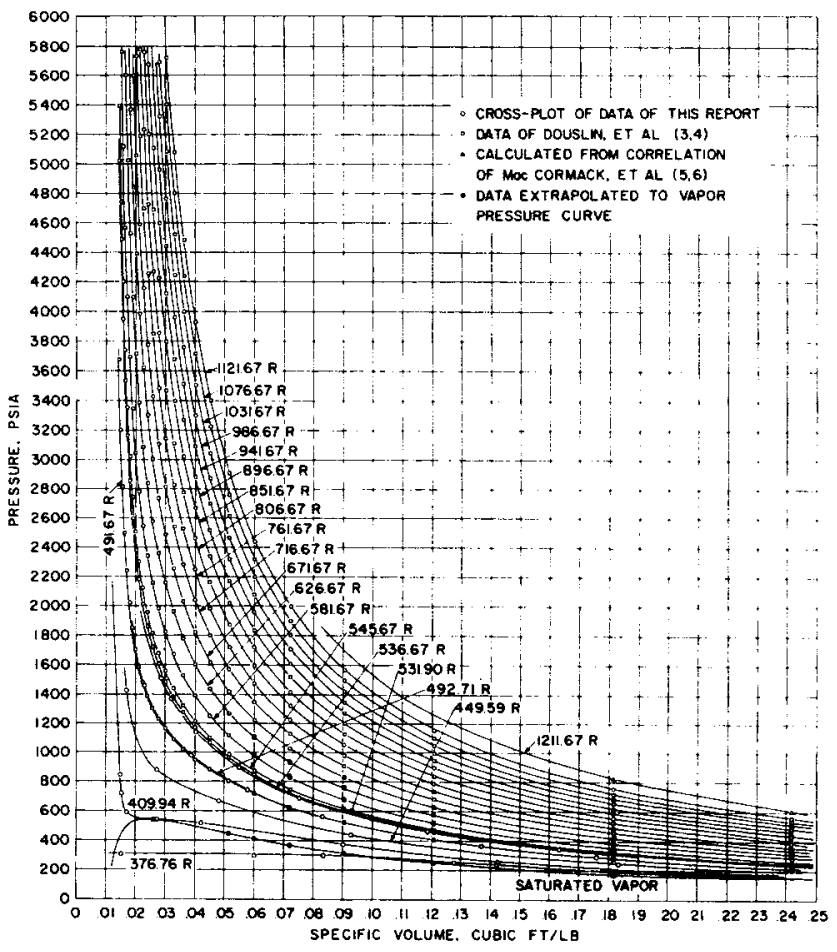

Fig. 4. Pressure-volume diagram for carbon tetrafluoride. 
Table 1. Comparison of the Martin Equation of State with Data of This Paper FOR CARBON TETRAFLUORIDE

\begin{tabular}{|c|c|c|c|c|c|c|}
\hline \multirow{2}{*}{$\begin{array}{c}\text { Temp., } \\
{ }_{\mathrm{O}}\end{array}$} & \multirow{2}{*}{$\begin{array}{l}\text { Specific } \\
\text { volume, } \\
\text { cu. ft. } / \mathrm{lb} \text {. }\end{array}$} & \multirow{2}{*}{$\begin{array}{c}\text { Pressure } \\
\text { observed, } \\
\text { lb./sq.in.abs. }\end{array}$} & \multirow{2}{*}{ 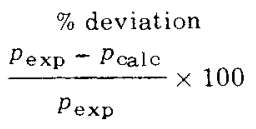 } & \multicolumn{3}{|c|}{ Reduced properties } \\
\hline & & & & $T_{r}$ & $P_{r}$ & $z$ \\
\hline \multirow[t]{7}{*}{531.90} & 0.16379 & 359.3 & 0.004 & 1.299 & 0.662 & 0.907 \\
\hline & 0.11929 & 476.9 & 0.056 & & 0.878 & 0.877 \\
\hline & 0.07583 & 699.2 & -0.159 & & 1.287 & 0.817 \\
\hline & 0.05549 & 900.1 & 0.008 & & 1.657 & 0.770 \\
\hline & 0.04093 & 1145.4 & 0.326 & & 2.109 & 0.723 \\
\hline & 0.03243 & 1378.7 & 0.030 & & 2.538 & 0.689 \\
\hline & 0.02895 & 1518.8 & -0.300 & & 2.796 & 0.678 \\
\hline \multirow[t]{6}{*}{492.71} & 0.17619 & 304.9 & 0.025 & 1.203 & 0.561 & 0.894 \\
\hline & 0.13715 & 379.2 & -0.090 & & 0.698 & 0.866 \\
\hline & 0.08378 & 567.7 & -0.292 & & 1.045 & 0.792 \\
\hline & 0.05809 & 748.8 & 0.056 & & 1.379 & 0.724 \\
\hline & 0.03907 & 983.0 & 0.132 & & 1.810 & 0.639 \\
\hline & 0.2314 & 1467.6 & -0.795 & & 2.702 & 0.565 \\
\hline \multirow[t]{5}{*}{449.59} & 0.18388 & 259.9 & 0.000 & 1.0980 & 0.479 & 0.872 \\
\hline & 0.09338 & 448.6 & 0.198 & & 0.826 & 0.764 \\
\hline & 0.04868 & 677.5 & 0.286 & & 1.247 & 0.602 \\
\hline & 0.02762 & 883.2 & -0.689 & & 1.626 & 0.445 \\
\hline & 0.01713 & 1432.9 & 0.220 & & 2.638 & 0.447 \\
\hline \multirow[t]{7}{*}{409.94} & 0.14297 & 278.5 & -0.063 & 1.0011 & 0.513 & 0.797 \\
\hline & 0.09082 & 382.4 & -0.045 & & 0.704 & 0.695 \\
\hline & 0.04261 & 527.7 & -0.048 & & 0.972 & 0.450 \\
\hline & 0.02776 & 543.0 & -0.752 & & 0.9997 & 0.302 \\
\hline & 0.01523 & 851.5 & -2.548 & & 1.568 & 0.259 \\
\hline & 0.01578 & 734.5 & -3.367 & & 1.334 & 0.229 \\
\hline & 0.01743 & 596.6 & -1.095 & & 1.098 & 0.208 \\
\hline \multirow[t]{5}{*}{376.76} & 0.14169 & 243.8 & 0.329 & 0.9201 & 0.449 & 0.752 \\
\hline & 0.12809 & 261.1 & 0.387 & & 0.4807 & 0.728 \\
\hline & 0.08402 & 309.1 & $0.013^{*}$ & & 0.570 & 0.565 \\
\hline & 0.06081 & 309.2 & $0.016^{*}$ & & 0.570 & 0.409 \\
\hline & 0.01580 & 309.2 & $0.016^{*}$ & & 0.570 & 0.106 \\
\hline
\end{tabular}

*Calculated from Chari's vapor pressure equation (I) since these points are in the two-phase region.

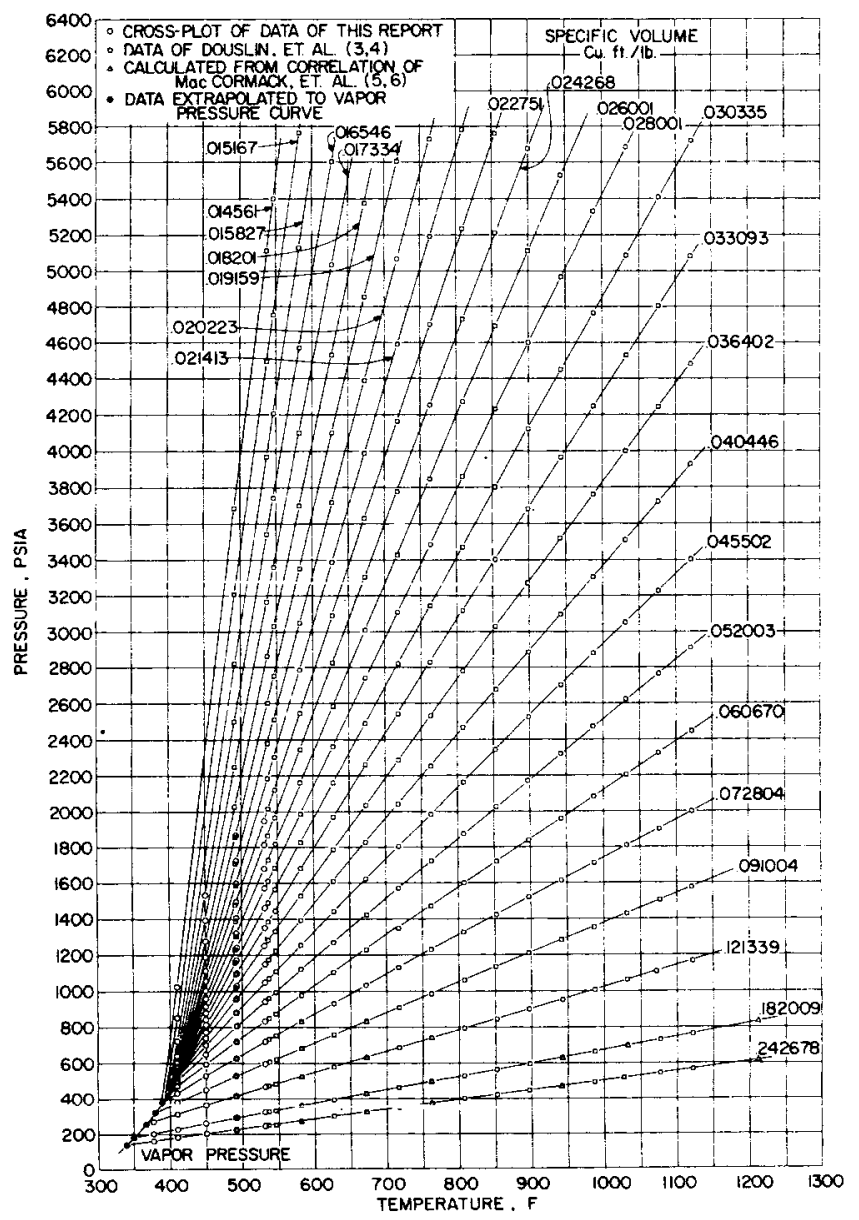

Fig. 5. Pressure-temperature diagram for carbon tetrafluoride. critical and at the extreme ends, as well as the downward curvature of the isometrics at the intermediate densities. The isometrics have been extended graphically to the vapor pressure curve, and the points of intersection are noted with the dark dots in Figure 5.

To check the generalized trends, the data have been plotted on a compressibility chart as shown in Figure 6. No disagreement is noticed between this compressibility plot and what has been observed from study of many other compounds.

In addition to showing the proper generalized trends, Figures 4, 5, and 6 also show good agreement between the data of this paper with those from the literature ( 3 to 6 ) in all regions of overlap.

\section{Algebraic Analysis}

Following the graphical analysis of the data, the next step was to analyze the data algebraically with an equation of state. Many equations of state have been proposed in literature. Probably the most exhaustive study on this subject of equations of state was recently reported by Martin (29). A logical interpretation of the various characteristics of P-V-T data has led Martin to the following form of the equation:*

$$
\begin{aligned}
p=\frac{R T}{v-b}+ & \frac{A_{2}+B_{2} T+C_{2} e^{-k T}}{(v-b)^{2}}+\frac{A_{3}+B_{3} T+C_{3} e^{-k T}}{(v-b)^{3}} \\
& +\frac{A_{4}+B_{4} T+C_{4} e^{-k T}}{(v-b)^{4}}+\frac{A_{5}+B_{5} T+C_{4} e^{-k T}}{(v-b)^{5}} \\
& +\frac{A_{6}+B_{6} T+C_{6} e^{-k T}}{e^{a \mathbf{v}}\left(1+c e^{a \mathbf{v}}\right)}
\end{aligned}
$$

*This equation will be called the Martin equation of state in this paper. 
This equation has built into its form and derivation all the observed properties of the $\mathrm{P}-\mathrm{V}-\mathrm{T}$ behavior. The constants, $A_{2}, B_{2}$, etc., $\cdots C_{6}$, are assigned values dependent on the data of the particular compound under study.

There are 15 constants in the temperature function of the equation of state, exclusive of $k, a, b, c$, which must be

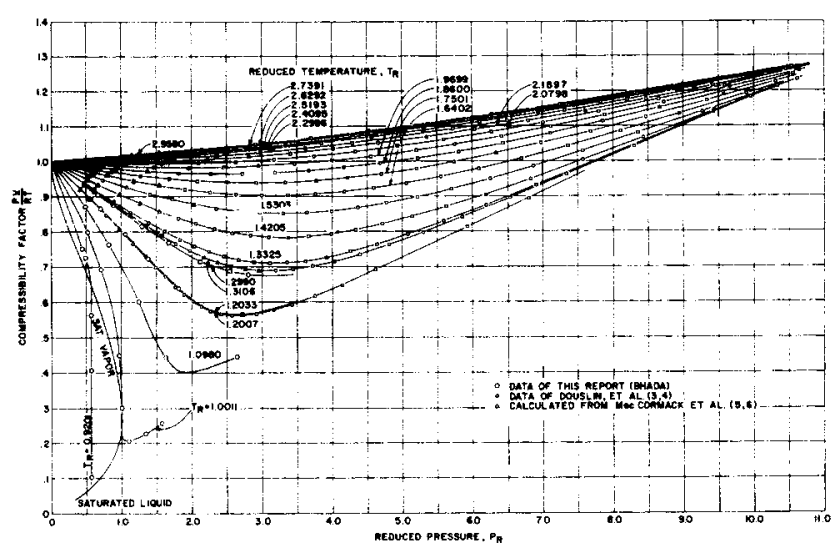

Fig. 6. Compressibility factor of carbon tetrafluoride.

Table 2. Final Input Parameters for the Martin

EQuation of State for Carbon Tetrafluoride

1. $T_{c}=409.48^{\circ} \mathrm{R} ., p_{c}=543.16 \mathrm{lb} . / \mathrm{sq}$. in.abs.,

$v_{c}=\frac{1}{39.06}=0.02560163 \mathrm{cu} . \mathrm{ft} . / \mathrm{b}$.

2. At $T_{c}, p=1,080 \mathrm{lb} . / \mathrm{sq}$. in.abs., $v=0.0145607 \mathrm{cu} . \mathrm{ft} . / \mathrm{lb}$.

3. $\left(d z / d p_{r}\right)_{P_{r}} \longrightarrow 0=-0.34$

$$
T_{r}^{r}=1
$$

4. $(d p / d v)_{p_{c}, r_{c}=0}$

5. $\left(d^{2} p / d \mathbf{v}^{2}\right)_{p_{C}}, T_{C}=0$

6. $a=725.0, b=0.00000, c=5 \times 10^{-7}$

7. $T^{\prime}=(0.800) T_{C}$

8. $T_{B}=935^{\circ} \mathrm{R}$.

9. $k=4.2 / T_{C}$

10. $\left(d^{2} p / d T^{2}\right)=0$

$(d p / d T)=36.55$

11. $\left(d^{2} p / d T^{2}\right) v^{\prime} c=0$

$(d p / d T)_{v_{c}}=9.60$

12. $(d p / d T)_{T \rightarrow \infty} V_{c}=1.061\left(R / \mathbf{v}_{C}\right)$

13. $\operatorname{Cr}\left(T_{B}\right)=0.0142$

14. $\operatorname{Cr}\left(T^{\prime}\right)=0.050$

15. Selected point

$T_{\text {sat }}=399.53^{\circ} \mathrm{R}$.

$P_{\text {sat }}=459.30 \mathrm{lb} . / \mathrm{sq} \cdot \mathrm{in} \cdot \mathrm{abs}$.

$v=0.01616 \mathrm{cu} . \mathrm{ft} . / \mathrm{lb}$. evaluated. Therefore, 15 input parameters (shown in Table 2) have been utilized in the evaluation of these constants. The method of arriving at the numerical values of these parameters for carbon tetrafluoride is similar to that described by Martin (29). The final selected values of these parameters are given in Table 2.

The latest paper by Martin (29) fully describes the logic behind the equation of state and the constants. The form of the equation given is capable of accurate representation of P-V-T behavior at densities as high as 2.5 times the critical. The method of solution for the constants, $A_{2}, B_{2}$, $\mathrm{C}_{2}$, etc., has been fully covered by Martin (29). The final forms of the constants derived for carbon tetrafluoride are shown in Table 3. It is believed that these constants give the best possible fit of the equation to the experimental data (that is, low deviations and least possible trends for data of this report as well as those from literature). Tables 1,4 , and 5 show the comparison of the experimental data of this paper as well as from literature with the calculated

Table 3. Constants for the Martin Equation of state FOR CARBON TETRAFLUORIDE

$$
\begin{aligned}
p=\frac{R T}{(\mathbf{v}-b)}+ & \frac{A_{2}+B_{2} T+C_{2} e^{-k T}}{(\mathbf{v}-b)^{2}}+\frac{A_{3}+B_{3} T+C_{3} e^{-k T}}{(\mathbf{v}-b)^{3}} \\
& +\frac{A_{4}+B_{4} T+C_{4} e^{-k T}}{(\mathbf{v}-b)^{4}}+\frac{A_{5}+B_{5} T+C_{5} e^{-k T}}{(\mathbf{v}-b)^{5}} \\
& +\frac{A_{6}+B_{6} T+C_{6} e^{-k T}}{e^{a \mathbf{v}}\left(1+c e^{a \mathbf{v}}\right)}
\end{aligned}
$$

where $A_{2}=-2.2937960$

$B_{2}=2.4545836 \times 10^{-3}$

$C_{2}=-1.8125736 \times 10^{+1}$

$A_{3}=1.2063702 \times 10^{-2}$

$B_{3}=1.7195172 \times 10^{-6}$

$C_{3}=1.2232951 \times 10^{-1}$

$A_{4}=-3.0017046 \times 10^{-4}$

$B_{4}=3.4565907 \times 10^{-7}$

$C_{4}=1.9662646 \times 10^{-2}$

$A_{5}=1.0070856 \times 10^{-6}$

$B_{5}=2.0376194 \times 10^{-9}$

$C_{5}=-2.7942103 \times 10^{-4}$

$A_{6}=3.2856989 \times 10^{6}$

$B_{6}=1.9199674 \times 10^{4}$

$C_{6}=1.4483858 \times 10^{9}$

$R=0.12193362$

$a=725.0$

$b=0.00$

$c=5.0 \times 10^{-7}$

$k=+4.2 / T_{0}$

$\mathrm{T}_{c}=409.48^{\circ} \mathrm{R}$.

$p$, lb./sq.in.abs.

\begin{tabular}{|c|c|c|c|c|c|c|}
\hline \multirow{2}{*}{$\begin{array}{c}\text { Temp., } \\
{ }^{\circ} \mathrm{R} .\end{array}$} & \multirow{2}{*}{$\begin{array}{l}\text { Specific } \\
\text { volume, } \\
\text { cu. ft. } / \mathrm{b} \text {. }\end{array}$} & \multirow{2}{*}{$\begin{array}{l}\text { Pressure } \\
\text { observed }\end{array}$} & \multirow{2}{*}{$\begin{array}{c}\% \text { deviation } \\
\frac{p_{\exp }-p_{\text {calc }}}{p_{\exp }} \times 100\end{array}$} & \multicolumn{3}{|c|}{ Reduced properties } \\
\hline & & & & $T_{r}$ & $P_{r}$ & $z$ \\
\hline \multirow[t]{9}{*}{491.67} & 0.242678 & 227.49 & -0.028 & 1.2007 & 0.419 & 0.921 \\
\hline & 0.121339 & 419.70 & -0.064 & & 0.773 & 0.849 \\
\hline & 0.072804 & 631.54 & -0.041 & & 1.163 & 0.767 \\
\hline & 0.052003 & 805.40 & 0.032 & & 1.483 & 0.699 \\
\hline & 0.036402 & 1024.37 & 0.068 & & 1.886 & 0.622 \\
\hline & 0.028001 & 1233.04 & -0.242 & & 2.270 & 0.576 \\
\hline & 0.020223 & 1713.19 & -0.531 & & 3.154 & 0.578 \\
\hline & 0.016546 & 2505.39 & 0.324 & & 4.613 & 0.692 \\
\hline & 0.014561 & 3689.12 & 0.254 & & 6.791 & 0.896 \\
\hline
\end{tabular}

$\mathrm{T},{ }^{\circ} \mathrm{R}$.

v, cu. ft./lb.

Table 4. Comparison of EQuation with Data of Douslin*

* Sample data only shown in this table. Complete comparison is given in reference 30 and has also been placed with the ADI. (See footnote on p. 688.) 
Table 5. Comparison of Equation with Correlation of MacCormack and Schneider

\begin{tabular}{|c|c|c|c|c|c|c|c|}
\hline \multirow{3}{*}{$\begin{array}{c}\text { Temp., } \\
\text { or. }\end{array}$} & \multirow{3}{*}{$\begin{array}{l}\text { Specific } \\
\text { volume, } \\
\text { cu. ft. } / \text { lb. }\end{array}$} & \multirow{3}{*}{$\begin{array}{l}\text { Pressure, } \\
\text { observed* }\end{array}$} & \multirow{3}{*}{$\begin{array}{l}\text { lb. } / \text { sq. in. } \\
\text { calc. }\end{array}$} & \multirow{3}{*}{$\begin{array}{c}\% \text { deviation } \\
\frac{p_{\exp }-p_{\text {calc }}}{p_{\text {exp }}} \times 100\end{array}$} & \multirow{2}{*}{\multicolumn{3}{|c|}{ Reduced properties }} \\
\hline & & & & & & & \\
\hline & & & & & $T_{r}$ & $P_{r}$ & $z$ \\
\hline \multirow[t]{5}{*}{491.67} & 0.242678 & 227.46 & 227.55 & -0.042 & 1.2007 & 0.419 & 0.921 \\
\hline & 0.121339 & 419.90 & 419.97 & -0.016 & & 0.773 & 0.849 \\
\hline & 0.091004 & 531.65 & 531.56 & 0.017 & & 0.979 & 0.807 \\
\hline & 0.072804 & 632.00 & 631.80 & 0.032 & & 1.164 & 0.768 \\
\hline & 0.060670 & 722.35 & 722.42 & -0.009 & & 1.330 & 0.731 \\
\hline \multirow[t]{2}{*}{671.67} & 0.242678 & 327.79 & 327.14 & 0.200 & 1.6402 & 0.603 & 0.970 \\
\hline & 0.121339 & 638.60 & 637.22 & 0.217 & & 1.176 & 0.946 \\
\hline \multirow[t]{2}{*}{761.67} & 0.242678 & 376.35 & 376.31 & 0.011 & 1.8600 & 0.693 & 0.984 \\
\hline & 0.121339 & 743.99 & 743.56 & 0.057 & & 1.370 & 0.972 \\
\hline \multirow[t]{2}{*}{941.67} & 0.242678 & 474.53 & 474.39 & 0.029 & 2.2996 & 0.874 & 1.003 \\
\hline & 0.182009 & 633.87 & 633.66 & 0.033 & & 1.167 & 1.005 \\
\hline \multirow[t]{2}{*}{$1,031.67$} & 0.242678 & 523.02 & 523.39 & -0.072 & 2.5194 & 0.963 & 1.010 \\
\hline & 0.182009 & 700.03 & 700.70 & -0.095 & & 1.289 & 1.012 \\
\hline $1,211.67$ & 0.242678 & 620.49 & 621.38 & -0.144 & 2.9590 & 1.142 & 1.019 \\
\hline
\end{tabular}

*A few selected points obtained from correlation of MacCormack and Schneider $(5,6)$.

values from the equation of state.* Also shown in Tables 1,4 , and 5 are the reduced properties $P_{r}$ and $T_{r}$, together with the $z$ values for each data point.

\section{CONCLUSIONS}

A variable-volume cell has been designed for observation of the (P-V-T) behavior of gases and liquids which does not use any liquid medium in contact with the compound under observation. The equipment consists of a bellows, in which the gas is confined, enclosed in a cylinder containing a fluid at the same pressure as the gas.

The P-V-T behavior of carbon tetrafluoride has been observed over a temperature range of $376^{\circ}$ to $532 \mathrm{R}^{\circ}$, a pressure range of 100 to $1,500 \mathrm{lb} . / \mathrm{sq}$. in. abs., and a specific volume range of 0.184 to $0.0152 \mathrm{cu}$. $\mathrm{ft} . / \mathrm{lb}$. (about 1.66 times the critical density). The data have been correlated by the Martin equation of state, as shown in Table 3 . This equation represents the observed data of this paper with an average deviation of $0.411 \%$ (average deviation is $0.236 \%$ for the literature data of Douslin et al. $(3,4))$.

It is concluded that data which are internally consistent as well as consistent with data from literature can be observed using the equipment of the study. The P-V-T cell is unique in that it utilizes stainless steel bellows with a $14: 1$ volume variation and with no liquid medium in contact with the compound under investigation.

\section{NOTATION}

$A_{2}-A_{6}=$ constants in the Martin equation of state

$a=$ constant in the Martin equation of state

$B_{2}-B_{6}=$ constants in the Martin equation of state

$b=$ constant in the Martin equation of state

$C r(T)=$ reduced third virial coefficient defined as $f_{3}(T) p^{2} / R^{2} T^{3}$

$C_{2}-C_{6}=$ constants in the Martin equation of state

$c=$ constant in the Martin equation of state

$k=$ curvature constant in the Martin equation of state

$p=$ pressure, $\mathrm{lb} . / \mathrm{sq}$. in. abs.

$p_{r}=$ reduced pressure, $p / p_{c}$

$p_{c}=$ critical pressure, $1 \mathrm{lb} . / \mathrm{sq}$. in. abs.

$p_{\mathrm{s} a t}=$ pressure along the vapor pressure curve, $\mathrm{lb} . / \mathrm{sq}$. in. abs.

$R=$ gas constant

$T=$ temperature, ${ }^{\circ} \mathrm{R}$.

* Table 4 shows comparison with the data of Douslin et al. $(3,4)$ for one temperature only; the complete comparison may be found in the original dissertation (30). Table 4 has also been deposited as document No. 01384 with the ASIS National Auxiliary Publications Service, c/o CCM Information Sciences, Inc. 909 Third Ave., New York 10022 and may be obtained for $\$ 2.00$ for microfiche or $\$ 5.00$ for photocopies.
$T_{r}=$ reduced temperature, $T / T_{c}$

$T_{c}=$ critical temperature, ${ }^{\circ} \mathrm{R}$.

$T^{\prime}=$ temperature at which $B\left(T^{\prime}\right) p_{c} / R T^{\prime}=z_{C}-1$

$T_{B}=$ Boyle temperature (at which $B\left(T_{B}\right) p_{c} / R T_{B}=0$ )

$T_{\text {sat }}=$ Temperature along the saturation curve, ${ }^{\circ} \mathrm{R}$.

$\mathbf{v}=$ specific volume, $\mathrm{cu}$. ft. $/ \mathrm{lb}$.

$\mathbf{v}_{c}=$ critical specific volume, cu.ft. $/ \mathrm{lb}$.

$z=$ compressibility factor, $p \mathbf{v} / R T$

\section{LITERATURE CITED}

1. Chari, N. C. S., “PhD. dissertation, Univ. Michigan, Ann Arbor (1960).

2. Martin, J. J., and Y. T. Hwang, AIChE J., 10, 89-91 (Jan. 1964).

3. Douslin, D. R., paper presented at the Second Symp. Thermophysical Properties, Princeton Univ. (Jan. 24-26, 1962).

4. $\ldots$ et al., J. Chem. Phys., 35, 1357-1366 (Oct. 1961).

5. Schneider, W. G., Can. J. Res., 27B, 339-352 (1949).

6. MacCormack, K. E., and W. G. Schneider, J. Chem. Phys., 19, 845-848, (July 1951).

7. Martin, J. J., and Y. C. Hou, AIChE J., 5 (2) (1959).

8. Ellington, R. T., and B. E. Eakin, Chem. Engr. Progr., 59, $80-88$ (Nov. 1963).

9. Beattie, J. A., Proc. Am. Acad. Arts Sci., 69, 389-405 (1934),

10. Kelso, E. A., and W. A. Felsing, Am. Chem. Soc. J., 62, 3132 $3135(1940)$.

11. Day, H. O., and W. A. Felsing, ibid., 74, 1951-1953 (1952).

12. Cherney, B. J., H. Marchman, and R. York, Ind. Engr. Chem. 41, 2653 (1949).

13. Kay, W. B., Am. Chem. Soc. J., 69, 1273-1277 (1947)

14. Bahlke, W. H., and W. B. Kay, Ind. Engr. Chem., 24, 219 (1932).

15. Keyes, F. G., and R. B. Brownlee, Am. Chem. Soc. J., 40, 25 (1918).

16. Smith, J. M. and C. J. Walters, Chem. Engr. Progr., 48, 337 (1952).

17. Sage, B. H., and W. N. Lacey, Trans. Am. Inst. Min. Met. Engr., 136, 136 (1940).

18. Michels, A., C. Michels, and H. Wonters, Am. Chem. Soc. J., 40, 25 (1918).

19. Schamp, H. W., E. A. Mason, A. C. B. Richardson, and A. Altman, Phys. Fluids, 1, 329-337 (Aug. 1958).

20. Connolly, J. F., and G. A. Kandalic, ibid., 3, 463-467 (MayJune 1960).

21. Douslin, D. R., R. T. Moore, J. P. Dawson, and G. Waddington, Am. Chem. Soc., 80, 2031-2038 (May 5, 1958).

22. Burnett, E. S., J. Appl. Mech., 3, 136-140 (1936).

23. Leland, T. W., R. Kobayashi, and F. B. Canfield, J. Chem. Engr. Data, 10, 92-96 (Apr. 1965).

24. Mueller, W. H., et al., AIChE J., 7, 267-272 (June 1961).

25. Bridgeman, P. W., "The Physics of High Pressure," G. Bell and Sons, London (1949).

26. Proc. Am. Acad. Arts Sci., 61, 57-99 (1926).

27. Bradbury, D., Trans. ASME, 73, 667-675 (1951).

28. Cutler, W. G. et al., J. Chem. Phys., 29, 727-733 (Oct. 1958).

29. Martin, J. J., Ind. Eng. Chem., 59, 34-52 (Dec. 1967).

30. Bhada, R. K., Ph.D. dissertation, Univ. Michigan, Ann Arbor (1968).

Manuscript received June 3,1969; revision received August

21, 1969: paper accepted September 8, 1969. 